\title{
Changes in the cellular immune system and circulating inflammatory markers of stroke patients
}

\author{
Chao Jiang ${ }^{1,2, *}$, Weixia Kong ${ }^{3, *}$, Yuejuan Wang ${ }^{1}$, Wendy Ziai ${ }^{2,4}$, Qingwu Yang ${ }^{5}$, \\ Fangfang Zuo ${ }^{1}$, Fangfang Li ${ }^{1}$, Yali Wang ${ }^{1}$, Hongwei $\mathrm{Xu}^{6}$, Qian $\mathrm{Li}^{2}$, Jie Yang ${ }^{2}$, Hong \\ Lu $^{7}$, Jiewen Zhang ${ }^{8}$ and Jian Wang ${ }^{1,2}$ \\ ${ }^{1}$ Department of Neurology, The Fifth Affiliated Hospital of Zhengzhou University, Zhengzhou, Henan, China \\ 2 Department of Anesthesiology/Critical Care Medicine, Johns Hopkins University, School of Medicine, Baltimore, MD, USA \\ ${ }^{3}$ Department of Ultrasonography, The Fifth Affiliated Hospital of Zhengzhou University, Zhengzhou, Henan, China \\ ${ }^{4}$ Department of Neurology, Johns Hopkins University, School of Medicine, Baltimore, MD, USA \\ ${ }^{5}$ Department of Neurology, Xinqiao Hospital, Third Military Medical University, Chongqing, China \\ ${ }^{6}$ Department of Radiology, The Fifth Affiliated Hospital of Zhengzhou University, Zhengzhou, Henan, China \\ 7 Department of Neurology, The First Affiliated Hospital of Zhengzhou University, Zhengzhou, Henan, China \\ ${ }^{8}$ Department of Neurology, People's Hospital of Zhengzhou University, Zhengzhou, Henan, China \\ * These authors have contributed equally to this work \\ Correspondence to: Chao Jiang, email: chaojzzu@126.com
} Jian Wang, email: jwang79@jhmi.edu

Keywords: ischemic stroke, lymphocyte subpopulations, circulating inflammatory markers, infection, immunosuppression Received: June 07, $2016 \quad$ Accepted: September 16, $2016 \quad$ Published: September 22, 2016

\section{ABSTRACT}

This study was designed to investigate dynamic changes in the cellular immune system and circulating inflammatory markers after ischemic stroke. Blood was collected from 96 patients and 99 age-matched control subjects for detection of lymphocyte subpopulations and inflammatory markers. We observed decreases in B cells, Th cells, cytotoxic T cells, and NK cells and an increase in regulatory $T$ (Treg) cells in stroke patients on days 1, 3, and 7. Serum levels of TNF-a, C-reactive protein (CRP), IL-4, IL-6, IL-10, IL-17, IL-23, and TGF- $\beta$ increased, whereas serum level of IFN-Y decreased at all time points after stroke. Stroke patients with infection exhibited a similar tendency toward changes in some lymphocyte subpopulations and inflammatory markers as stroke patients without infection. After controlling for NIH Stroke Scale (NIHSS), we observed no differences in lymphocyte subpopulations between patients with anterior circulation stroke and those with posterior circulation stroke at any time point. The splenic volume correlated positively with the percentages of B cells, Th cells, and cytotoxic T cells, but negatively with Treg cells on day 3 after stroke. Infections were associated with splenic volume, leukocyte counts, percentage of Treg cells, and serum levels of CRP, IL-10, and IFN-Y on day 3. Lesion volume correlated positively with CRP, IL-6, and IL-23, but negatively with IFN-Y on day 3. The NIHSS showed a positive relation with IL-6 and IL-10 on day 3. Ischemic stroke has a profound effect on the systemic immune system that might explain the increased susceptibility of stroke patients to infection.

\section{INTRODUCTION}

Studies have shown that the probability of infection in patients with stroke is $21-65 \%[1,2]$. Although clinical studies suggest that reduction of bulbar reflexes, drowsiness, dysphagia, and subsequent aspiration strongly increase the incidence of infections $[1,3,4]$, recent preclinical evidence suggests that stroke-induced immunosuppression may also play a decisive role in infection risk $[1,5]$.

Stroke-induced immunodepression syndrome (SIDS) may involve interaction between the cellular 
immune system and circulating inflammatory markers [68]. Some research has shown that regulatory T (Treg) cells, interleukin (IL)-4, IL-10, and transforming growth factor (TGF)- $\beta$ contribute to the process of immunodepression [9-11]. Moreover, TGF- $\beta$ and IL-10 are essential for the differentiation of Treg cells [12]. On the other hand, IL17 and IL-23 are critical for the differentiation of some types of helper T cells (such as Th17) and contribute to the inflammatory reaction process [12-14]. Several studies have shown that the percentages of cytotoxic $\mathrm{T}$ cells, natural killer (NK) cells, and B lymphocytes, and serum levels of TNF- $\alpha$, IFN- $\gamma$, C-reactive protein (CRP), IL-4, IL-6, IL-10, and TGF- $\beta$ are altered after stroke [15-17]. However, few studies have examined the dynamic changes in percentages of Treg cells and Th cells, or in the levels of IL-17 and IL-23 after stroke. No studies have investigated differences in the cellular immune system and circulating inflammatory markers between stroke patients with and without infection, or assessed the influence of vascular territories on the severity of SIDS. Furthermore, little is known about the correlation between splenic volume and lymphocyte subpopulations, or the relationship between lymphocyte subpopulations, cytokine levels, and infections in patients with ischemic stroke.

Therefore, we evaluated changes in the frequency or percentage of peripheral blood lymphocyte subpopulations and levels of inflammatory markers in blood samples of patients during the first 7 days after ischemic stroke. We also measured spleen size and rates of pneumonia and urinary tract infection. Then we ascertained the correlation between splenic volume and lymphocyte subpopulations, and the influence of vascular territories on the severity of SIDS. We also evaluated the relationship between lymphocyte subpopulations, cytokine levels, and infections and determined whether changes in circulating inflammatory markers are associated with stroke lesion volume and/or neurologic function in patients with cerebral infarction.

\section{RESULTS}

\section{Baseline characteristics of the two groups}

The stroke group comprised 59 men and 37 women with an average age of 58.9 years (range, 22-91). The control group was composed of 56 men and 43 women with an average age of 60.8 years (range, 20-86). Based on the Trial of Org 10172 in Acute Stroke Treatment (TOAST) classification [18], strokes were attributed to large-artery atherosclerosis (17), cardioembolic stroke (33), small-artery occlusion or lacunes (11), other determined cause (3), and undetermined cause (32). The differences in demographic variables and comorbidities between the two groups are shown in Tables 1 and 2 [19]. Three patients with stroke died within 3 days of onset and five died within 7 days.

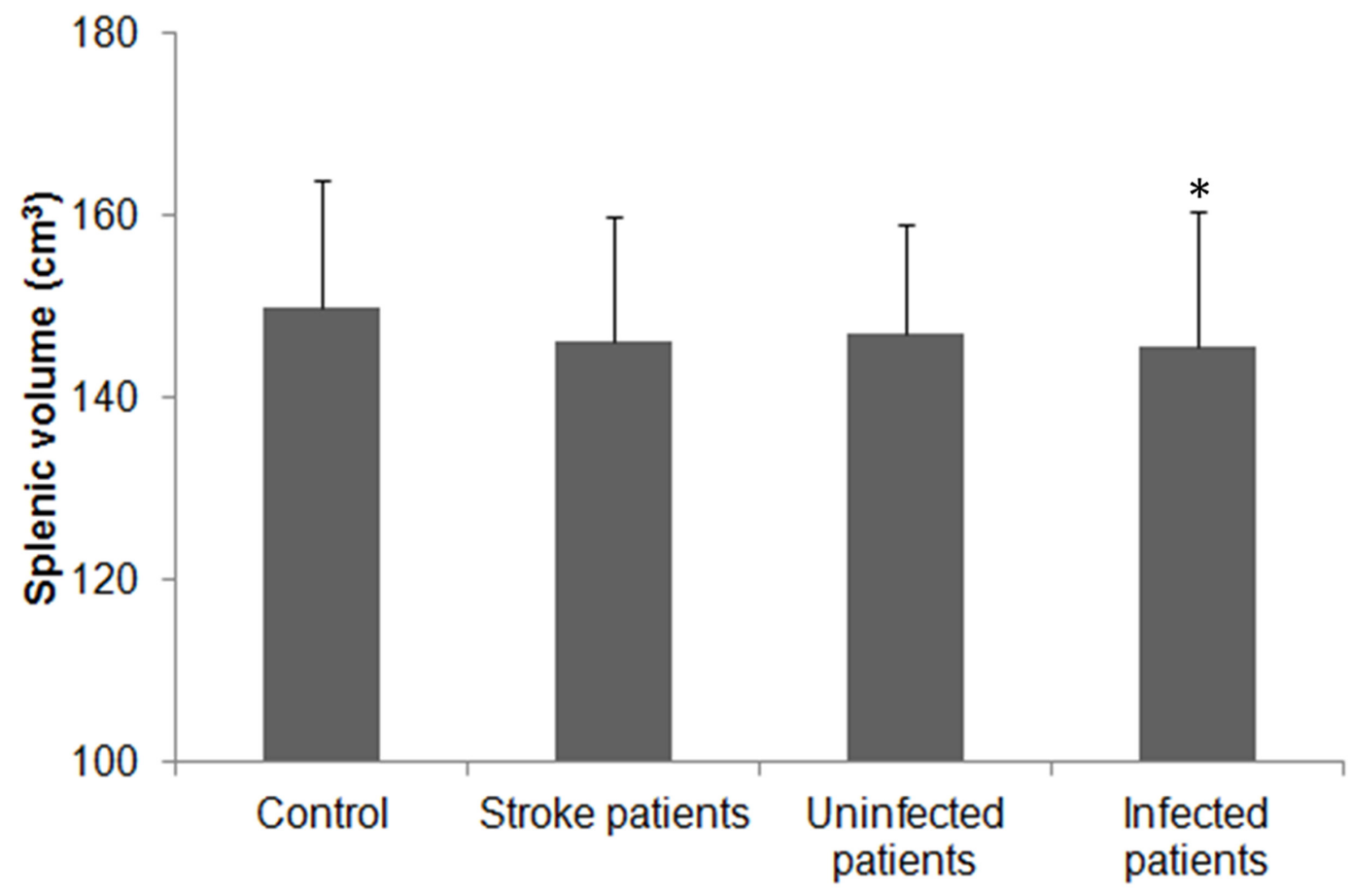

Figure 1: Splenic volume in patients with ischemic stroke. Splenic volume of control subjects and patients with ischemic stroke (total, with and without infectious complications). The splenic volumes of patients with ischemic stroke were slightly reduced but did not differ significantly from that of the control group $(p>0.05)$. Splenic volume did not differ significantly between uninfected stroke patients and control subjects $(p>0.05)$, but it was significantly lower in patients with infection than in control subjects $\left({ }^{*} p<0.05\right)$. 
Table 1: Characteristics of control subjects and stroke patients

\begin{tabular}{|c|c|c|c|c|}
\hline Characteristic & Control group $(n=99)$ & Stroke group $(n=96)$ & Statistical quantity & $p$ \\
\hline Age $($ mean \pm SD) & $60.79 \pm 18.30$ & $58.93 \pm 16.44$ & $t=0.744$ & 0.458 \\
\hline Sex (male) & 56 & 59 & $\chi^{2}=0.032$ & 0.858 \\
\hline Hypertension & 27 & 29 & $\chi^{2}=0.032$ & 0.858 \\
\hline Diabetes & 21 & 26 & $\chi^{2}=0.511$ & 0.475 \\
\hline Dyslipidemia & 31 & 30 & $\chi^{2}=0.129$ & 0.720 \\
\hline Obesity $(\mathrm{BMI} \geq 30)(\%)$ & 14.1 & 17.7 & $\chi^{2}=0.464$ & 0.496 \\
\hline Smoking (\%) & 21.2 & 22.9 & $\chi^{2}=0.082$ & 0.774 \\
\hline AB points ${ }^{\mathrm{a}}$ & & & $t=5.850$ & 0.119 \\
\hline 0 & 48 & 32 & & \\
\hline 1 & 39 & 43 & & \\
\hline 2 & 9 & 15 & & \\
\hline 3 & 3 & 6 & & \\
\hline Atrial fibrillation & 5 & 7 & $\chi^{2}=0.424$ & 0.362 \\
\hline LVEF & $64.50 \pm 7.58$ & $62.70 \pm 7.79$ & $t=1.640$ & 0.103 \\
\hline Posterior circulation stroke & N/A & 29 & $\mathrm{~N} / \mathrm{A}$ & N/A \\
\hline Time since stroke (mean $\pm \mathrm{SD}$ ) & $\mathrm{N} / \mathrm{A}$ & $(7.65 \pm 2.51) \mathrm{h}$ & N/A & $\mathrm{N} / \mathrm{A}$ \\
\hline NIHSS score, median (range) & $\mathrm{N} / \mathrm{A}$ & $9(7-13)$ & N/A & $\mathrm{N} / \mathrm{A}$ \\
\hline Lesion volume, $\mathrm{cm}^{3}($ mean $\pm \mathrm{SD})$ & $\mathrm{N} / \mathrm{A}$ & $23.89 \pm 9.49$ & N/A & N/A \\
\hline
\end{tabular}

$\mathrm{AB}=$ atherosclerotic burden; $\mathrm{BMI}=$ body mass index; $\mathrm{LVEF}=$ left ventricular ejection fraction; N/A = not applicable.

${ }^{a} \mathrm{AB}$ was evaluated with the following scores: 0 points, $<3$ vascular risk factors and no effect on other vascular territories (coronary artery disease or peripheral artery disease); 1 point, $\geq 3$ risk factors; 2 points, 1 vascular territory affected (in addition to cerebrovascular); and 3 points, 2 vascular territories affected. AB scores of 2 and 3 were independent of the number of vascular risk factors.

Table 2: Characteristics of stroke patients with or without infection

\begin{tabular}{|l|l|l|l|l|}
\hline Characteristic & Infection $(\boldsymbol{n}=\mathbf{5 1})$ & No infection $(\boldsymbol{n}=\mathbf{4 5})$ & Statistical quantity & $\boldsymbol{p}$ \\
\hline Age $($ mean \pm SD) & $59.06 \pm 14.40$ & $58.79 \pm 18.66$ & $t=0.078$ & 0.938 \\
\hline Sex $($ male) & 27 & 22 & $\chi^{2}=0.157$ & 0.692 \\
\hline Hypertension & 16 & 13 & $\chi^{2}=0.070$ & 0.791 \\
\hline Diabetes & 15 & 11 & $\chi^{2}=0.299$ & 0.585 \\
\hline Dyslipidemia & 17 & 13 & $\chi^{2}=0.220$ & 0.639 \\
\hline Obesity (BMI $\geq 30)(\%)$ & 19.6 & 15.6 & $\chi^{2}=0.269$ & 0.604 \\
\hline Smoking (\%) & 25.5 & 20 & $\chi^{2}=0.408$ & 0.523 \\
\hline AB points & & & $t=1.426$ & 0.699 \\
\hline 0 & 19 & 13 & & \\
\hline 1 & 25 & 18 & & \\
\hline 2 & 9 & 6 & & \\
\hline 3 & 5 & 1 & $\chi^{2}=1.016$ & 0.314 \\
\hline Atrial fibrillation & 5 & 2 & $t=0.701$ & 0.485 \\
\hline LVEF & $62.10 \pm 8.31$ & $63.22 \pm 7.34$ & $\chi^{2}=4.187$ & 0.041 \\
\hline Posterior circulation stroke & 20 & 9 & $t=3.205$ & 0.002 \\
\hline NIHSS score, median (range) & $9(7-15)$ & $8(6-10)$ & $t=3.888$ & $<0.001$ \\
\hline Lesion volume, $\mathrm{cm}^{3}$ (mean \pm SD) & $27.20 \pm 9.90$ & $20.15 \pm 7.50$ & & \\
\hline
\end{tabular}

$\mathrm{AB}=$ atherosclerotic burden; $\mathrm{BMI}=$ body mass index; $\mathrm{LVEF}=$ left ventricular ejection fraction.

${ }^{a} \mathrm{AB}$ was evaluated with the following scores: 0 points, $<3$ vascular risk factors and no effect on other vascular territories (coronary artery disease or peripheral artery disease); 1 point, $\geq 3$ risk factors; 2 points, 1 vascular territory affected (in addition to cerebrovascular); and 3 points, 2 vascular territories affected. AB scores of 2 and 3 were independent of the number of vascular risk factors. 


\section{Spleen size and incidence of infection}

The mean splenic volume was not significantly smaller in the stroke group $\left(146.25 \pm 13.71 \mathrm{~cm}^{3}\right)$ than in the control group $\left(150.05 \pm 27.71 \mathrm{~cm}^{3}, p=0.055\right)$, but it was significantly smaller in stroke patients with infection $(n=51 ; 145.54 \pm 15.10)$ than in control subjects $(p=$ 0.041 ). No significant difference was observed between infected patients and uninfected patients $(147.05 \pm 12.01$ $\mathrm{cm}^{3}$ ), or between uninfected patients and control subjects ( $p=0.591$ and 0.146 , respectively; Figure 1). Infections occurred in $51(53.1 \%)$ of 96 ischemic stroke patients
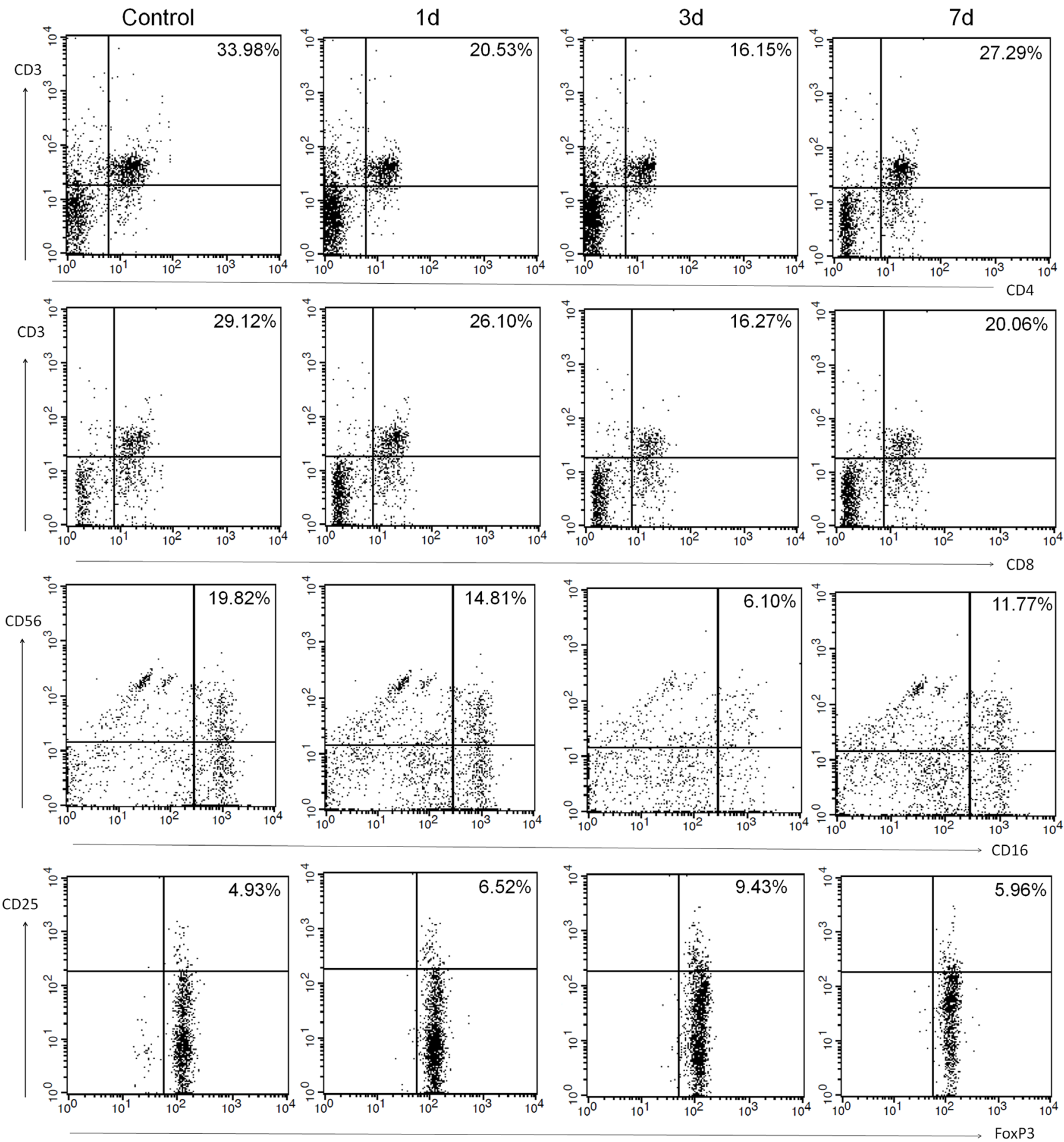

Figure 2: Representative flow cytometric analyses of blood lymphocyte subpopulations in control subjects and in patients with ischemic stroke on days 1,3 and 7: Th cells $\left(\mathrm{CD3}^{+} \mathrm{CD}^{+}\right)$, cytotoxic $\mathrm{T}$ cells $\left(\mathrm{CD3}^{+} \mathrm{CD8}^{+}\right)$, $\mathrm{NK}$ cells $\left(\mathrm{CD16}^{+} \mathrm{CD56}^{+}\right)$, and Treg cells $\left(\mathrm{CD4}^{+} \mathrm{CD25}^{+} \mathrm{FoxP3}^{+}\right)$. 

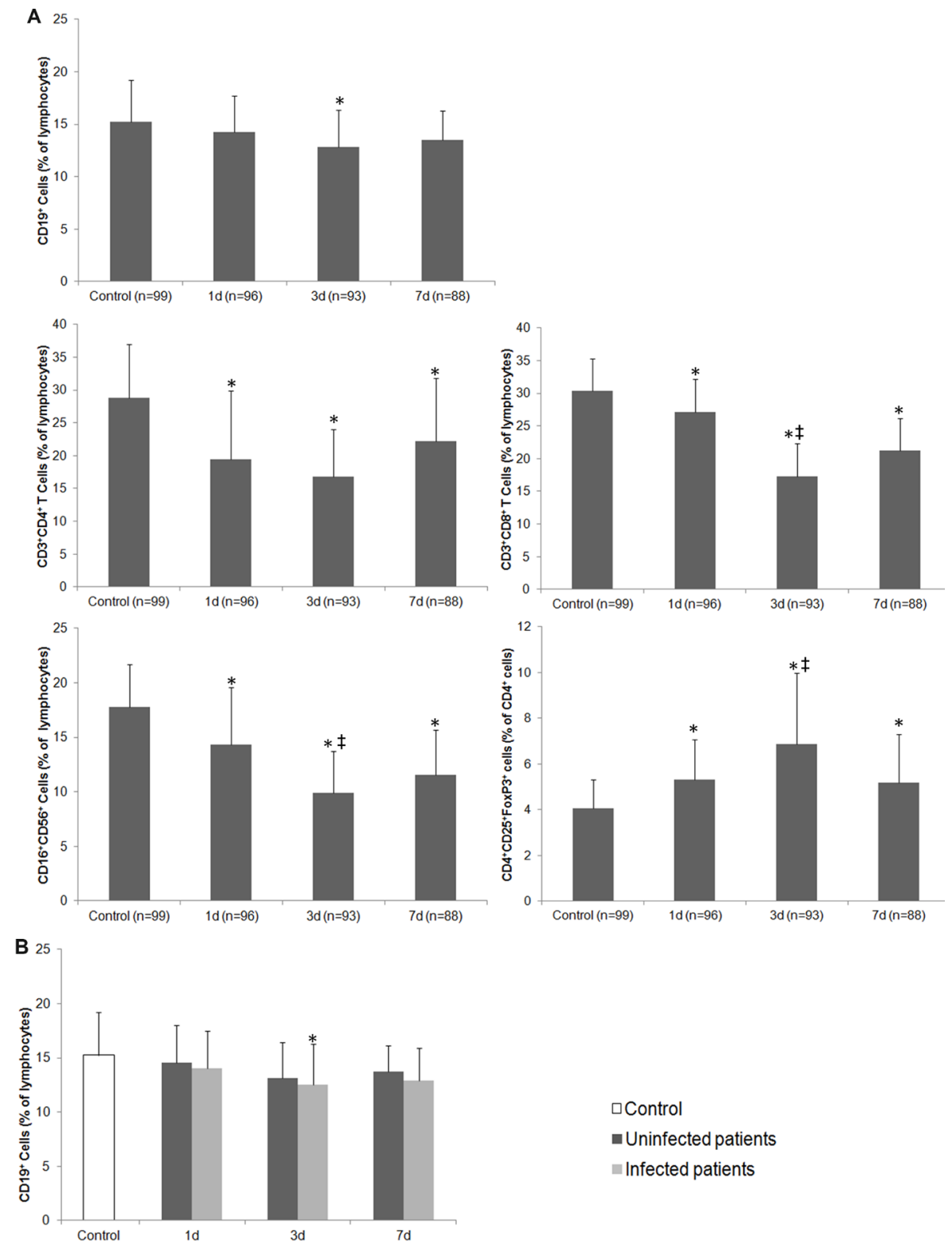

$\square$ Control

- Uninfected patients

- Infected patients
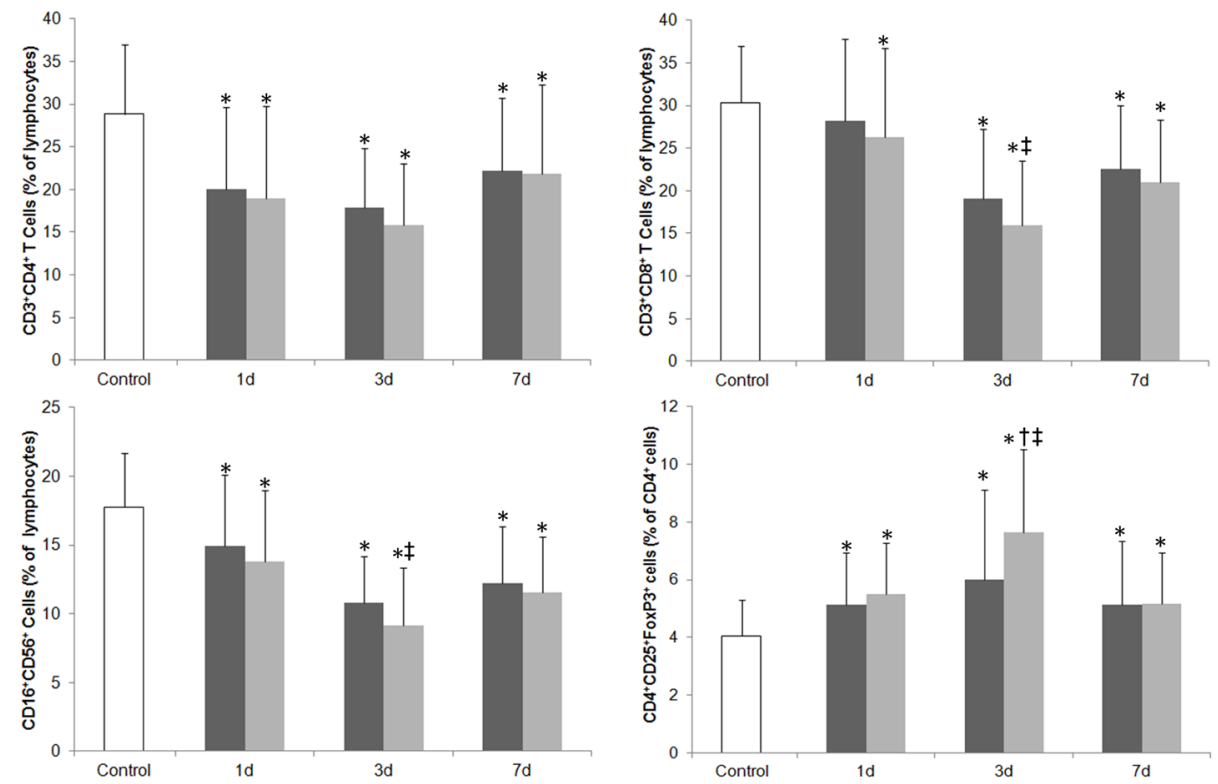

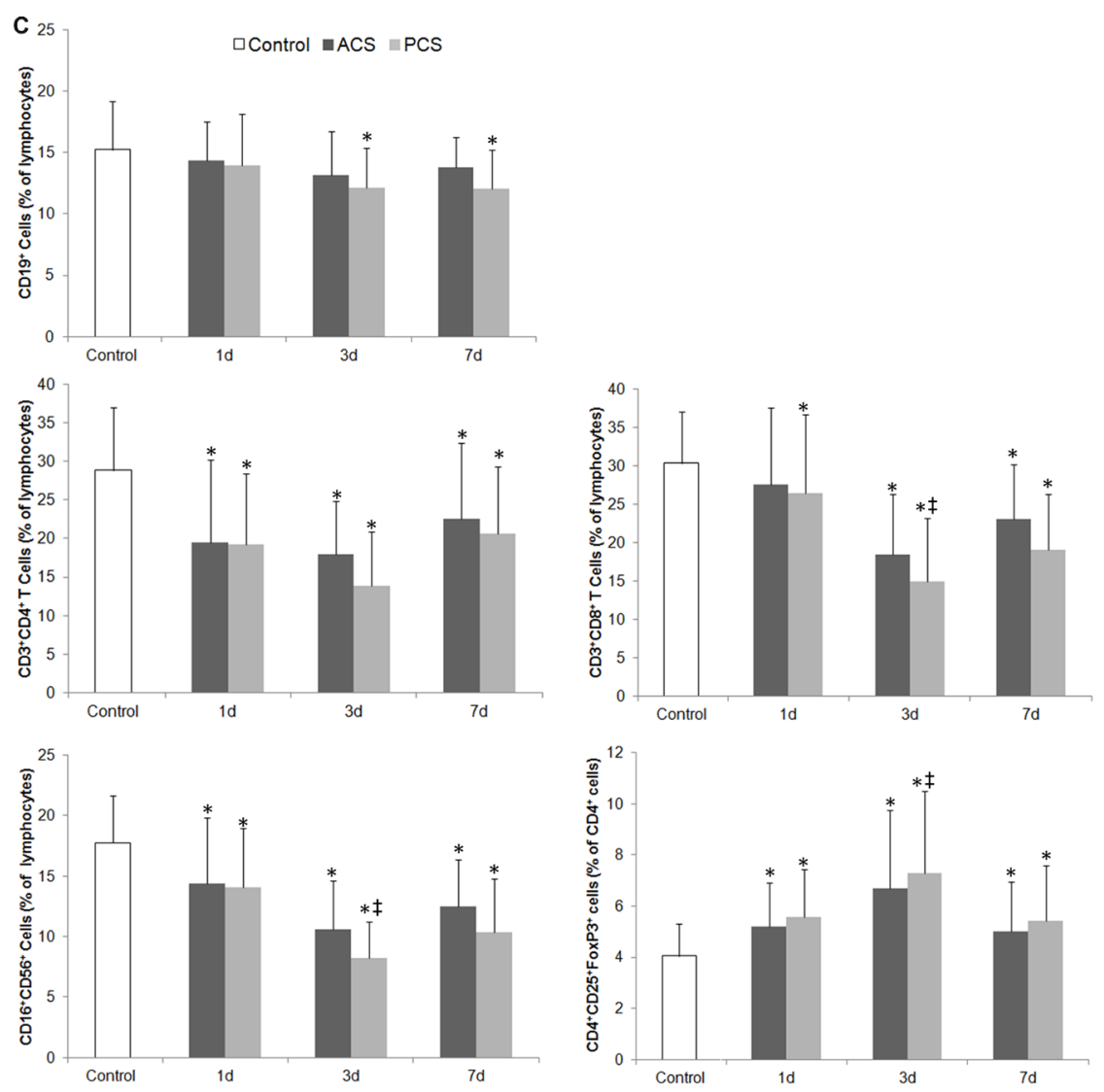

Figure 3: Changes in the cellular immune system of patients with ischemic stroke. A. The percentage of lymphocyte subpopulations in control subjects and in stroke patients on days 1, 3 and 7. B. The percentage of lymphocyte subpopulations in control subjects and in stroke patients with and without infectious complications on days 1,3 and 7. C. The percentage of lymphocyte subpopulations in control subjects and in patients with anterior circulation strokes (ACS) and posterior circulation strokes (PCS) on days 1, 3 and 7 after controlling for NIHSS. ${ }^{*} p<0.05 v s$. controls; ${ }^{\dagger} p<0.05 v s$. stroke patients without infections; ${ }^{\star} v s$. day 1 after stroke. Data represent mean $\pm \mathrm{SD}$.

during the first week of hospitalization $(5.1 \pm 2.8$ days); $36(37.5 \%)$ developed pneumonia, and $20(20.8 \%)$ developed a urinary tract infection. Among the patients with infections, 11 (11.5\%) developed sepsis. All patients diagnosed with a bacterial infection received antimicrobial agents according to their symptoms and signs, routine blood and urine laboratory test results, and pathogenic examination results.

\section{Lymphocyte subpopulations}

The temperature of the control group was $36.2^{\circ} \mathrm{C}$ $(\mathrm{SD}=0.45)$ on the date of blood collection. The temperature of the stroke group was $37.2^{\circ} \mathrm{C}(\mathrm{SD}=0.61)$ on day $1,37.7^{\circ} \mathrm{C}(\mathrm{SD}=0.94)$ on day 3 , and $36.8^{\circ} \mathrm{C}(\mathrm{SD}$ $=0.73)$ on day $7(\mathrm{~F}=102.77 ; p<0.01 v s$. control on all days). The median number of leukocytes in the control group was $5.23 \times 10^{9} / \mathrm{L}$, whereas the median in the stroke group was $11.96 \times 10^{9} / \mathrm{L}, 9.37 \times 10^{9} / \mathrm{L}$, and $10.41 \times 10^{9} / \mathrm{L}$ on days 1,3 , and 7 , respectively $(\mathrm{F}=70.99 ; p<0.01$ $v s$. control on all days). Representative dot plots of flow cytometric analyses in Figure 2 show blood lymphocyte subpopulations in stroke patients and control subjects. The percentages of Th cells, cytotoxic T cells, and NK cells were lower in the stroke group than in the control group on days 1,3 , and 7 (all $p<0.05$ ), but the percentage of B lymphocytes was lower than control only on day 3 ( $p<$ 0.05 ); the percentage of Treg cells was increased in stroke patients on all three days when compared with that in the control group (all $p<0.01$; Figure $3 \mathrm{~A}$ ). When patients were stratified into infected and uninfected groups, we observed that the percentage of B lymphocytes was lower in infected patients than in controls on day 3. Notably, we found similar changes in lymphocyte subpopulation percentages in infected and uninfected groups at most of the three time points when compared with populations in the control subjects (Figure 3B). However, only the percentage of Treg cells was higher in infected patients than in uninfected patients on day 3 after stroke onset $(p<$ 0.05 ), and no differences were found in the percentages of B cells, Th cells, cytotoxic T cells, and NK cells between infected patients and uninfected patients at any time points (all $p>0.05$; Figure 3B). When patients were stratified into anterior circulation stroke (ACS) and posterior 
Table 3: Correlation coefficients between spleen size and lymphocyte subpopulations on day 3 in stroke patients

\begin{tabular}{|l|l|l|l|l|l|}
\hline Parameter & B cells & Th cells & Cytotoxic T cells & NK cells & Treg cells \\
\hline$r$ & 0.347 & 0.228 & 0.223 & 0.091 & -0.264 \\
\hline$p$ & $0.001^{*}$ & $0.023^{*}$ & $0.026^{*}$ & 0.378 & $0.008^{*}$ \\
\hline
\end{tabular}

* Statistically significant.

$\mathrm{NK}=$ natural killer; $\mathrm{Th}=$ helper $\mathrm{T}$; Treg $=$ regulatory $\mathrm{T}$.

Table 4: Multivariate analysis: the relationship between cytokine levels, lymphocyte subpopulations, and infections in stroke patients

\begin{tabular}{|l|l|l|l|}
\hline Parameter (day 3) & OR & 95\% CI & $\boldsymbol{p}$ \\
\hline Splenic volume & 0.120 & $0.019-0.799$ & $0.030^{*}$ \\
\hline Leukocyte counts & 1.366 & $1.119-1.666$ & $0.002^{*}$ \\
\hline Treg cells & 1.232 & $1.069-1.421$ & $0.004^{*}$ \\
\hline CRP & 2.036 & $1.035-4.005$ & $0.039^{*}$ \\
\hline IL-10 & 1.290 & $1.065-1.563$ & $0.009 *$ \\
\hline IFN- $\gamma$ & 0.913 & $0.842-0.994$ & $0.040^{*}$ \\
\hline
\end{tabular}

*Statistically significant.

$\mathrm{CI}=$ confidence interval; $\mathrm{CRP}=\mathrm{C}$-reactive protein; IFN = interferon; IL-10 = interleukin 10; OR = odds ratio; Treg = regulatory $\mathrm{T}$.

circulation stroke (PCS), we observed that the percentage of B lymphocytes was lower in patients with PCS than in controls on day 3; percentages of Th cells, cytotoxic T cells, and NK cells were lower and percentage of Treg cells were higher in patients with ACS and PCS than in control subjects at most of the three time points (Figure 3C). Further analysis revealed no significant differences in lymphocyte subpopulations between patients with ACS and PCS at any time point after controlling for NIHSS (all $p>0.05$; Figure 3C).

\section{Serum level of circulating inflammatory markers and cytokines}

The serum levels of TNF- $\alpha$, CRP, TGF- $\beta$, IL- 4 , IL6, IL-10, IL-17, and IL-23 were all increased on days 1, 3, and 7 after stroke when compared with levels in the control group (all $p<0.05$; Figure 4A); however, the content of IFN- $\gamma$ was lower in stroke patients than in controls at each time point ( $p<0.01$; Figure 4A). Moreover, serum levels of TNF- $\alpha$ and IL- 6 decreased, whereas IL10 increased in stroke patients between day 1 and day 3 (all $p<0.05$, Figure 4A). When patients were stratified by infection status, we observed increases in TNF- $\alpha$, CRP, TGF- $\beta$, IL-4, IL-6, IL-10, IL-17, and IL-23, and a decrease in IFN- $\gamma$ in both uninfected and infected patients when compared with control subjects at most of the three time points (Figure 4B). We also compared infected and uninfected patients at each time point. Serum CRP level was higher in infected patients than in uninfected patients, but IFN- $\gamma$ level was lower in the infected patients on day 3 after stroke onset (both $p<0.05$ ). Serum levels of IL10 in infected patients were not different from those in uninfected patients on days 3 and 7 after stroke onset ( $p>$ 0.05 ; Figure 4B).

\section{Correlation between spleen size and lymphocyte subpopulations in stroke patients}

On day 3 after stroke onset, we found an independently positive correlation between splenic volume and the percentages of circulating B cells, Th cells, and cytotoxic T cells (all $p<0.05$; Table 3 ). However, the percentage of circulating Treg cells was negatively correlated with splenic volume $(p<0.05$; Table 3$)$.

\section{Relationship between cytokine levels, lymphocyte subpopulations, and infections}

Adjusted logistic regression analysis revealed that infection was independently associated with splenic volume, leukocyte counts, the percentage of Treg cells, and the serum levels of CRP, IL-10, and IFN- $\gamma$ on day 3 after stroke (all $p<0.05$; Table 4).

\section{Correlation between lesion volume, NIHSS, and circulating inflammatory markers}

Statistical evaluation revealed an independently positive correlation between lesion volume and CRP, IL6 , and IL-23 on day 3 after stroke onset (all $p<0.05$ ). In addition, the serum level of IFN- $\gamma$ was negatively associated with lesion volume on day 3 after stroke ( $p$ $<0.05$; Table 5). However, the NIHSS at stroke onset showed an independent positive association only with IL-6 and IL-10 on day 3 (all $p<0.05$; Table 5). 

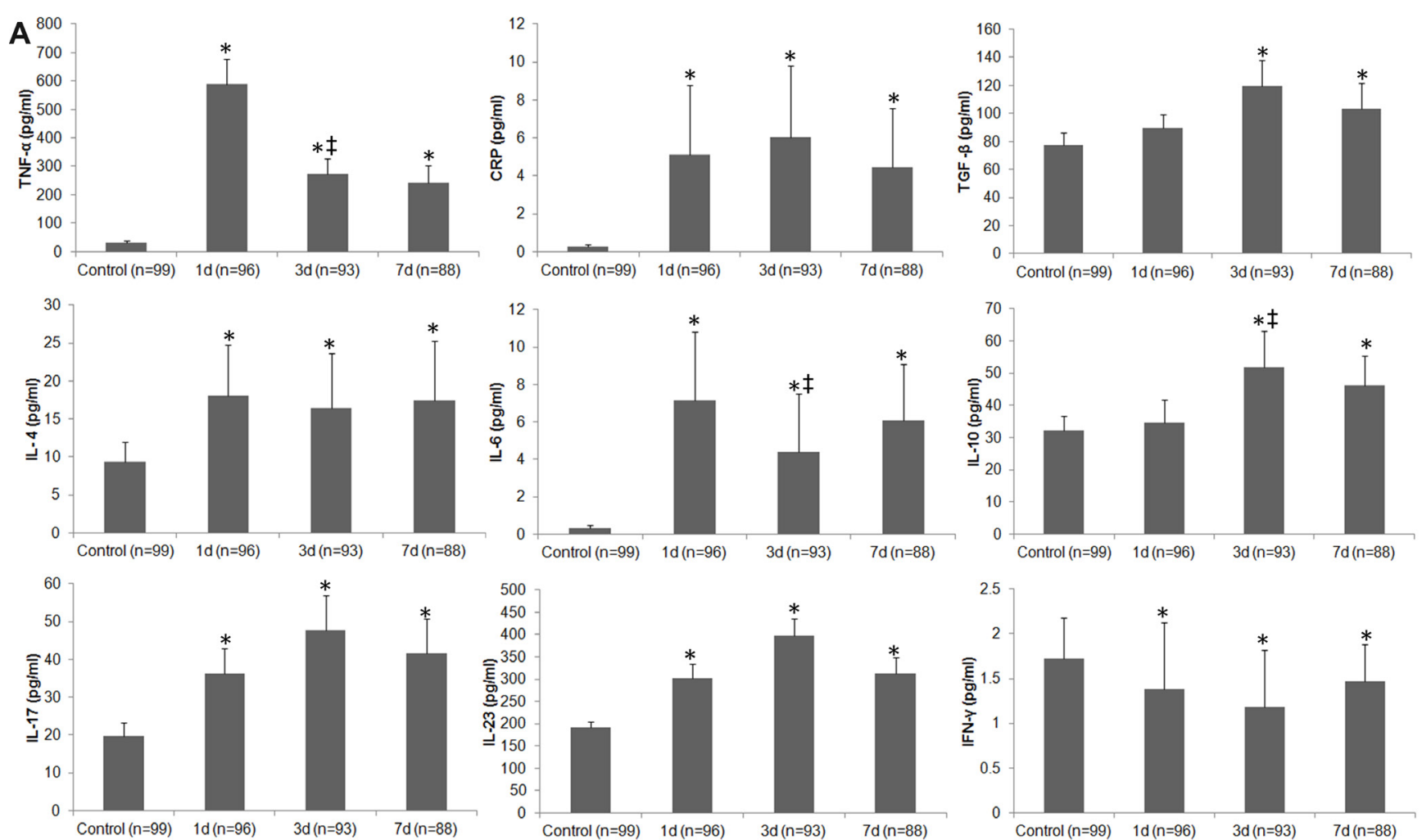

B
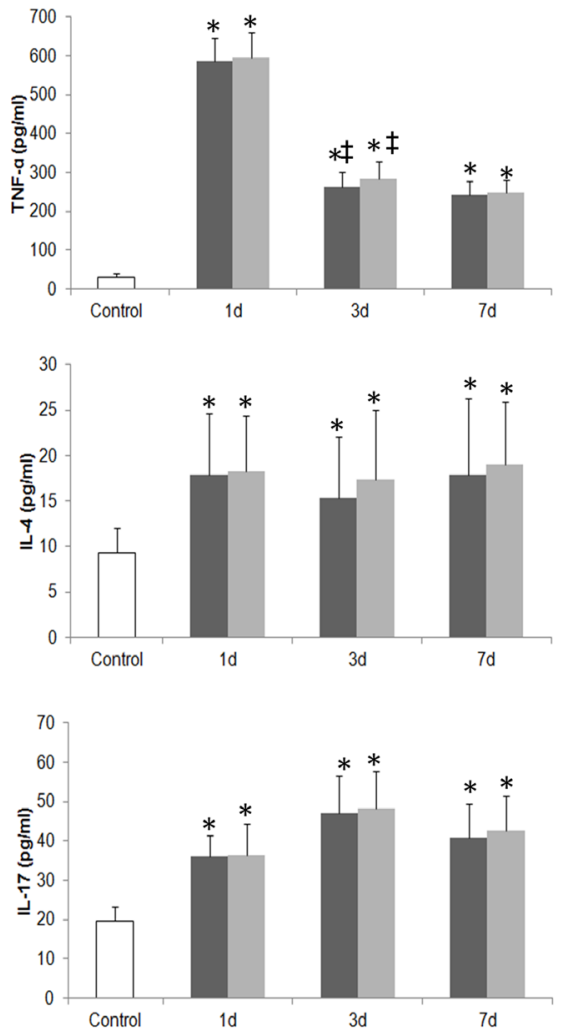

$\square$ Control $\square$ Uninfected patients $\backsim$ Infected patients
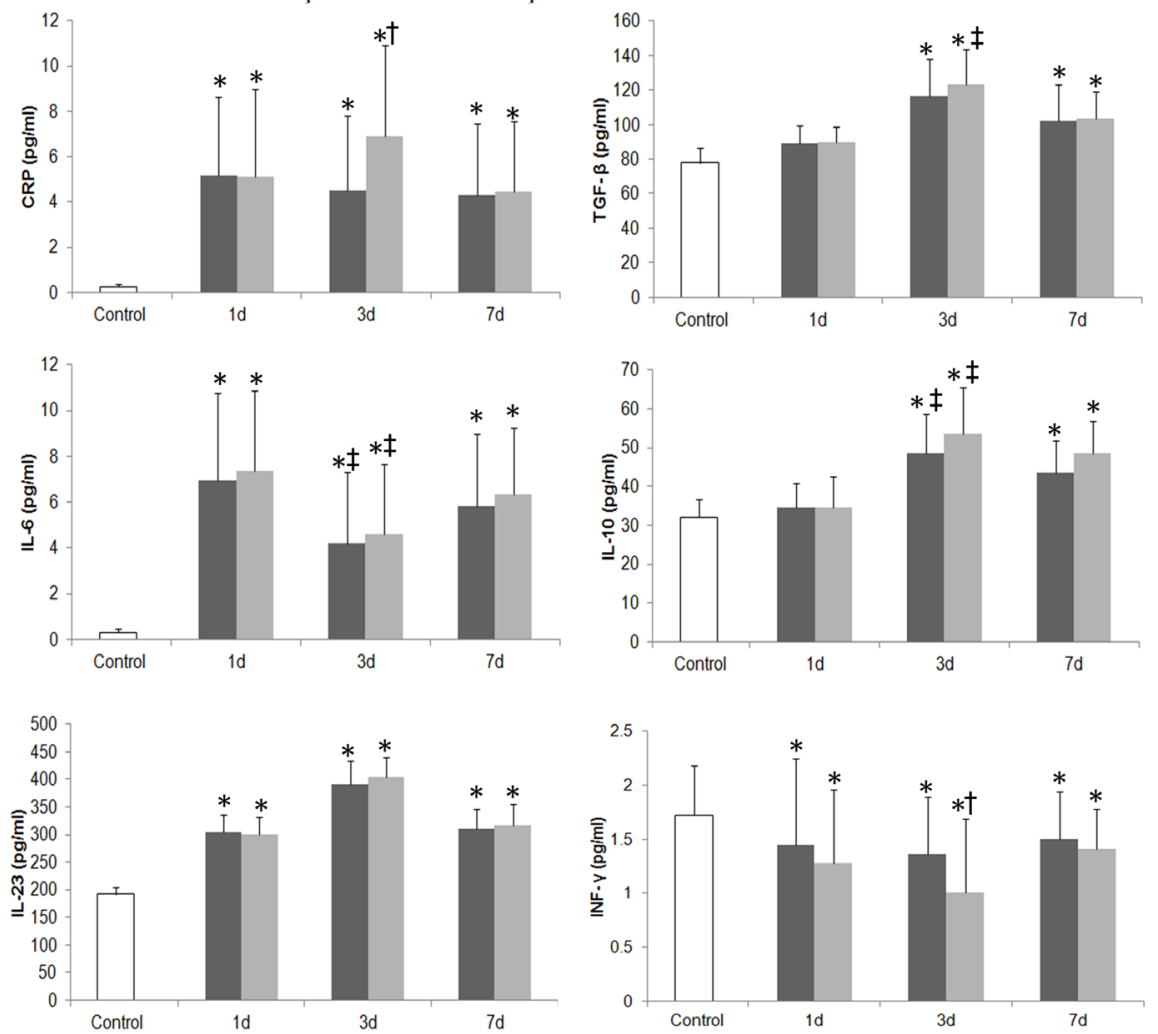

Figure 4: Differences in circulating inflammatory markers between control subjects and patients with ischemic stroke. A. Changes in serum levels of inflammatory markers in control subjects and in stroke patients on days 1,3, and 7. B. Changes in serum levels of inflammatory markers in control subjects and in stroke patients with and without infectious complications on days 1,3 and $7 .{ }^{*} p$ $<0.05 v s$. controls; ${ }^{\dagger} p<0.05 v$ s. stroke patients without infections; ${ }^{\ddagger} v s$. day 1 after stroke. Data represent mean $\pm \mathrm{SD}$. 
Table 5: Correlation coefficients between circulating inflammatory markers and lesion volume/NIHSS on day 3 after stroke in patients with infection

\begin{tabular}{|l|c|c|c|c|c|c|c|c|c|}
\hline & TNF- $\boldsymbol{\alpha}$ & CRP & IL-4 & IL-6 & IL-10 & TGF- $\boldsymbol{\beta}$ & IL-17 & IL-23 & IFN- $\boldsymbol{~}$ \\
\hline LV & & & & & & & & & \\
\hline$r$ & 0.201 & 0.340 & 0.020 & 0.296 & 0.030 & 0.025 & 0.109 & 0.312 & -0.386 \\
\hline$p$ & 0.157 & $0.015^{*}$ & 0.891 & $0.035^{*}$ & 0.834 & 0.864 & 0.447 & $0.026^{*}$ & $0.005^{*}$ \\
\hline NIHSS & & & & & & & & & \\
\hline$r$ & 0.181 & 0.271 & 0.206 & 0.289 & 0.835 & 0.093 & 0.191 & 0.030 & -0.038 \\
\hline$p$ & 0.204 & 0.055 & 0.147 & $0.040^{*}$ & $<0.001^{*}$ & 0.516 & 0.180 & 0.833 & 0.793 \\
\hline
\end{tabular}

*Statistically significant.

$\mathrm{CRP}=\mathrm{C}$-reactive protein; IFN = interferon; IL = interleukin; LV = lesion volume; NIHSS = National Institutes of Health Stroke Scale; TGF = transforming growth factor; TNF = tumor necrosis factor.

\section{DISCUSSION}

In our study population, $53.1 \%$ of patients with ischemic stroke developed an infection, and the splenic volume of those patients decreased significantly in the early phase when compared with that of control subjects. Patients with ischemic stroke exhibited significant changes in the percentage of lymphocyte subpopulations and serum levels of inflammatory markers. The changes were similar in infected and uninfected patients when compared with control subjects, but changes in some lymphocyte subpopulations and certain inflammatory markers were more profound in infected patients than in uninfected patients. The splenic volume correlated positively with the percentages of B cells, Th cells, and cytotoxic T cells, but negatively with Treg cells after stroke. No significant difference in lymphocyte subpopulations was observed between patients with ACS and PCS after controlling for NIHSS. Infections were associated with splenic volume, leukocyte counts, the percentage of Treg cells, and serum levels of CRP, IL-10, and IFN- $\gamma$. Serum levels of CRP, IL-6, IL-10, and IL-23 were significantly correlated with lesion volume and/or NIHSS in patients with ischemic stroke. The results suggest that changes in the cellular immune system and circulating inflammatory markers may be associated with SIDS and clinical severity of the stroke.

Recent studies in rodents have shown that the spleen contracts in response to acute ischemic stroke $[6,20,21]$. In our clinical study, we observed only a slight contraction of the spleen in patients with ischemic stroke on day 3 after symptom onset and no significant difference in size from that of controls, consistent with findings from a previous study [22]. Further analysis of our results revealed that, after controlling for age, gender, and body mass index, the spleen of stroke patients with infection contracted significantly on day 3 after symptom onset when compared with that of control subjects. Our findings support the notion that a decrease in splenic volume may be associated with the occurrence of SIDS.
Previous reports are conflicting in regard to the effect of stroke on the frequency or percentage of Treg cells [7, 22-24]. Similar to our previous findings in an animal model [22], we found that the percentage of Treg cells in the lymphocyte population increased, whereas the percentages of Th cells, cytotoxic T cells, NK cells, and $\mathrm{B}$ lymphocytes all significantly decreased during the early phase after ischemic stroke. However, we only found significant difference in the percentage of Treg cells between patients with and without infection on day 3 after stroke onset. Because the inflammatory response is complex, we cannot exclude the possibility that a mixed consequence of infection itself may influence the cellular immune system and circulating inflammatory markers of stroke patients. Th cells aggravate inflammatory response, whereas Treg cells exert immunosuppressive effects in the process of inflammation [25, 26]. Some research has suggested that the imbalance in $\mathrm{Th} / \mathrm{Treg}$ cells may contribute to immunosuppression [25]. Our results indicate that after ischemic stroke, the percentage of Treg cells increases while the percentages of Th cells, cytotoxic $\mathrm{T}$ cells, and NK cells decrease. These results support the notion that cellular immunity is depressed after ischemic stroke. We also evaluated the correlation between spleen size and lymphocyte subpopulations in this study. Previous research has indicated that SIDS may be caused by splenic cell death as well as an increased presence of $\mathrm{CD}^{+} \mathrm{FoxP}^{+}$ regulatory $\mathrm{T}$ cells [26]. Other research also showed that Treg cells are produced in the thymus as a mature cell population [26, 27]. Although our study illustrated that splenic volume correlated positively with the percentages of circulating B cells, Th cells, and cytotoxic T cells, but negatively with the percentage of circulating Treg cells after stroke, the mechanism that underlies changes in the cellular immune system and splenic volume needs additional investigation.

Cytokines such as IL-4, IL-10, and TGF- $\beta$ have immunodepressive ability $[9,10,28,29]$. In our study, the serum levels of TNF- $\alpha$, CRP, IL-4, and IL-10 were all significantly increased in stroke patients, whereas, the 
serum level of IFN- $\gamma$ was decreased compared with that in control subjects. The alterations in CRP and IFN- $\gamma$, were similar as above in stroke patients with and without infections. One prior study reported that a decrease in IFN- $\gamma$ secretion contributed to spontaneous bacterial infections in stroke patients [30]. IFN- $\gamma$ from Th cells is essential for host survival and enhances CD8 T cell function during infection $[31,32]$. IL-10 and TGF- $\beta$ are essential for the differentiation of Treg cells $[13,33]$. Just as IL-10 and TGF- $\beta$ contribute the differentiation of Treg cells, IL-17 and IL-23 contribute to the differentiation of Th cells [25]. Though we found an imbalance in Th/Treg cells, our research did not show a reduction in IL-17 or IL-23 in patients with ischemic stroke, a finding that may relate to the increase in frequency of total leukocytes in the early phase of stroke. These data indicate that changes in the circulating inflammatory markers complement alterations in the cellular immune system after ischemic stroke, which may contribute to or be a manifestation of post-stroke infection.

The incidence of pneumonia and urinary tract infection among stroke patients was $53.1 \%$ in our study but $21-65 \%$ in other studies $[1,2]$. The incidence of infection in stroke patients was affected by NIHSS, lesion volume, age, gender, smoking, history of diabetes, and stroke subtype [34-37]. Patients with PCS always develop dysphasia, which is associated with pneumonia [3, 37]. The percentage of patients with PCS in our study was higher than that in a previous report [38]. More patients with PCS plus a higher smoking rate may have led to a higher infection rate in our study than in some previous reports $[24,39,40]$. The association between serum IL-10 level and infections in stroke patients has been reported $[17,41]$. In this study, we further researched the relationship between lymphocyte subpopulations, cytokine levels, and infections after ischemic stroke. Adjusted logistic regression analysis of our data indicated that infections were not only associated with serum levels of IL-10, but also correlated with splenic volume, leukocyte counts, the percentage of Treg cells, and serum levels of CRP and IFN- $\gamma$.

Previous reports have shown that TNF- $\alpha$, IFN- $\gamma$, IL-6, IL-17, IL-23, and some monocytes are detrimental in the pathologic process of stroke [42-46], whereas Treg cells, IL-4, IL-10, and TGF- $\beta$ are major cerebroprotective modulators of post-ischemic inflammatory brain damage [47-49]. Studies also have shown that lesion volume correlates with IL-6 level after ischemic stroke [50]. Here, we showed that IFN- $\gamma$ was negatively correlated with lesion volume on day 3 after stroke, but that CRP, IL-6, and IL-23 were positively correlated with lesion volume at that time point. However, only IL-6 and IL10 were positively correlated with NIHSS on day 3 after stroke. These results indicate that immunologic changes were also associated with the degree of brain injury and the prognosis of patients with ischemic stroke. Although a crude association between admission CRP level and short-term functional outcome of stroke has been reported $[51,52]$, we did not identify an association between the serum CRP and NIHSS in our study, probably because of a relatively high incidence of infection in our patients.

SIDS occurs immediately after stroke in animals and patients $[39,53]$. Some research has revealed that the nadir for frequency of $\mathrm{CD}^{+}$and $\mathrm{CD}^{+}$cells is on day 0 in stroke patients, suggesting that cellular immunodepression precedes infectious complications in humans [39]. Therefore, the first blood collection in this study might have been too late to show initial immunodepression. However, like other clinical studies of traumatic brain injury and stroke $[17,54]$, we showed that substantial decreases or increases in the percentage of lymphocyte subpopulations and serum levels of inflammatory markers are delayed compared with those shown in animal studies. Others have shown that aspirin, statins, and the inflammatory reaction itself may alter some of the inflammatory parameters [1]. Because most stroke patients in our study received aspirin and statins before the first blood draw, and infection occurs in the acute phase of stroke, we cannot determine whether the use of these drugs delayed changes in the systemic immune system or if the inflammatory reaction itself influenced the systemic immune system after stroke. Although our study revealed that the percentage of Treg cells and serum levels of CRP and INF- $\gamma$ differ significantly between infected and uninfected patients on day 3 , we cannot fully exclude the influence of hospital admission-associated anxiety and stress on the systemic immune system.

Our study is limited because it involved only one academic center. Validation in additional cohorts is needed to confirm our findings. Additionally, we assessed the splenic volume only on day 3 after stroke. Longterm outcome data were not available for this cohort. We did not observe significant differences in lymphocyte subpopulations between patients with ACS and PCS after controlling for NIHSS, possibly because of the small sample size. Despite these limitations, we showed the dynamic changes in the percentage of lymphocyte subpopulations and the relationship between lymphocyte subpopulations, cytokine levels, and infections. We also established a correlation between spleen size and lymphocyte subpopulations, and the effects of vascular territories on the severity of SIDS in the early phase of ischemic stroke. It would be interesting to analyze the predictive value of the initial levels of inflammation (which likely occur before infection). The knowledge gained will be useful for the treatment of ischemic stroke and its infectious complications.

\section{CONCLUSIONS}

Ischemic stroke has a profound impact on the systemic immune system, and changes in the cellular 
immune system and circulating inflammatory markers may be associated with development of SIDS. Changes in the percentage of some lymphocyte subpopulations and in the serum levels of some inflammatory cytokines may reflect the degree of brain damage and the status of immunosuppression in ischemic stroke patients. Because infection may influence the recovery of stroke patients, regulating the imbalance in $\mathrm{Th} /$ Treg cells and associated cytokines may offer novel strategies for the treatment of stroke and related infections.

\section{MATERIALS AND METHODS}

\section{Study population}

Ninety-six patients with acute ischemic stroke were recruited into this study. Study entry criteria were the occurrence of an acute ischemic stroke within the previous $12 \mathrm{~h}$, a score of at least 4 on the NIHSS at admission (because changes in the cellular immune system and circulating inflammatory markers were influenced by lesion volume in an animal model of hemorrhagic stroke [55]), and patient age of at least 18 years. Computed tomography (CT) and MRI scans were used for the diagnosis of all patients on admission. Exclusion criteria included clinical signs of infection on admission (e.g., pneumonia, urinary tract infection), abnormal laboratory test results (e.g., routine blood and urine, erythrocyte sedimentation rate, CRP, and calcitonin element), malignant tumor, participation in another interventional trial, immunologic disorders prior to stroke, usage of any medications (before or after stroke) known to interfere with cytokine signaling, intravenous or intra-arterial infusion of recombinant tissue plasminogen activator therapy during hospitalization, preceding or ongoing antibiotic therapy within the last $24 \mathrm{~h}$, and immunosuppressant therapy within the last 30 days. Ninety-nine age-matched controls were also recruited. All of the control subjects came from the health checkup center of the Fifth Affiliated Hospital of Zhengzhou University, and their health status was known before physical examination and routine laboratory tests. The exclusion criteria were the same as those described above. Patient data and blood samples were handled in accordance with the published International Health Guidelines (Declaration of Helsinki, 2008). The study protocol was approved by the local ethics committee according to the World Medical Association as outlined in the Declaration of Helsinki. The families of all stroke patients and control subjects signed informed consent for aseptic peripheral venous puncture.

\section{Criteria for pneumonia or urinary tract infection}

Infection was defined according to the previous PANTHERIS study [56]. Pneumonia was diagnosed by the presence of at least one of the $\mathrm{A}$ and one of the $\mathrm{B}$ criteria. Criteria A: abnormal respiratory examination, pulmonary infiltrates on chest $\mathrm{x}$-ray; Criteria B: productive cough with purulent sputum, microbiological cultures from lower respiratory tract or blood cultures, leukocytosis, and elevation of CRP. For the diagnosis of urinary tract infection, two of the following criteria were included: fever $\left(>38.0^{\circ} \mathrm{C}\right)$, urine sample positive for nitrite, leukocyturia, and significant bacteriuria. Infection also was diagnosed if temperature was above $38.0^{\circ} \mathrm{C}$ on at least two determinations and the patient had leukocytosis and positive blood cultures, but no determined focus.

\section{Measurement of spleen size}

One certified sonographer measured spleen size using a GE Vivid E9 ultrasound machine and a phased sector array (5 to $1 \mathrm{MHz}$ ) transducer (GE Healthcare, New York, NY, USA) [21, 57]. The use of abdominal ultrasound for assessment of splenic volume has been validated previously against CT scan and autopsy measurements. The length, thickness, and width of the spleen at the splenic hilum level were measured in all patients on day 3 after stroke onset and in control subjects on the day after they signed the consent. Measurements were made in the sagittal (longitudinal) and transverse planes (measurement of width), and the maximum dimension was recorded in each plane. We calculated the final splenic volume as the average of three sets of these measurements (which have the least degree of variation among them) using the standard prolate ellipsoid formula, as has been reported previously [21]. The formula incorporated the product of one-dimensional diameters $(\mathrm{W} \times \mathrm{T} \times \mathrm{L})$ into the equation $\mathrm{V}=(\mathrm{W} \times \mathrm{T} \times \mathrm{L} \times \pi / 6)$, where $\mathrm{V}$ is the ellipsoid volume, $\mathrm{W}$ is width, $\mathrm{T}$ is thickness, and $\mathrm{L}$ is length [21]. The measured volume was adjusted for patient height, weight, and gender as previously described [21].

\section{Flow cytometry}

Peripheral blood samples $(5 \mathrm{~mL})$ were drawn from control subjects on the day after they signed the consent and from patients on days 1, 3, and 7 after stroke onset. Peripheral blood mononuclear cells were isolated within 2 $\mathrm{h}$ after blood draw. We used flow cytometry to determine the percentage of each lymphocyte subset within peripheral blood lymphocytes: CD45 for lymphocytes; CD3 and CD4 for Th cells; CD3 and CD8 for cytotoxic T cells; CD56 and CD16 for NK cells; CD19 for B lymphocytes; CD4, CD25, and FoxP3 for Treg cells (all 
antibodies from BD Pharmingen, San Diego, CA). Cells were phenotyped by four-color flow cytometry on a FACSCalibur flow cytometer using CELLQuest software (BD Biosciences, San Jose, CA, USA). Lymphocytes were gated based on a previous report [58]. Dead cells were excluded if aqua amine-reactive dye was positive. Treg cells were gated within the $\mathrm{CD} 4^{+}$cells. Other lymphocyte subsets were gated within the viable lymphocyte gate [58]. Based on the results of a routine blood test, the number of leukocytes was also recorded on admission.

\section{ELISA}

Using blood samples collected from patients and control subjects as described in the flow cytometry section, we measured protein concentration with the bicinchoninic acid assay kit (BCA; Pierce, Appleton, WI, USA). The total protein concentration was adjusted to $1 \mathrm{mg} / \mathrm{mL}$. The concentrations of TNF- $\alpha, \mathrm{CRP}, \mathrm{IL}-4, \mathrm{IL}-$ 6, IL-10, IL-17 (Sigma-Aldrich, St. Louis, MO, USA), IFN- $\gamma$ (eBioscience, San Diego, CA), TGF- $\beta$ (active; R\&D Systems, Minneapolis, MN), and IL-23 (BioLegend, San Diego, CA, USA) were quantified by ELISA kits. Levels of TNF- $\alpha$, CRP, IL-4, IL-6, IL-10, and IL-17 were measured within the range of the standard curve. The measurement range for the IFN- $\gamma$ kit was 0.016 to $10 \mathrm{pg} /$ $\mathrm{mL}$, that for the TGF- $\beta$ kit was 31.2 to $2000 \mathrm{pg} / \mathrm{mL}$, and that for the IL-23 kit was 31.3 to $2000 \mathrm{pg} / \mathrm{mL}$.

\section{Assessment of lesion volume in patients with ischemic stroke}

All MRI scans were acquired on a 3.0-Tesla system (Philips Medical System, Bothell, WA, USA) according to a previously described imaging protocol within 2 days after stroke onset [59]. The lesion volume was assessed as previously reported in patients with ischemic stroke [60]. We saved all diffusion-weighted imaging (DWI) scans in Digital Imaging and Communications in Medicine format for importation into ImageJ software using Sync Measure 3D plugin software (National Institutes of Health, Bethesda, MD). We used these data to calculate infarct areas extracted for evaluation. Areas of infarction on DWI were highlighted by interactively setting a threshold of 3000 over the signal value. Then the threshold image was analyzed by using the particles command in Image J. The voxel size of each image was determined and used to calculate the infarction volume (1 voxel represents 1.875 x 1.875 x $5.0 \mathrm{~mm}$ ).

\section{Data presentation and statistical analysis}

Statistical analysis was carried out with SPSS 13.0 (SPSS Inc., Chicago, IL, USA). Data are presented as mean (SD) or median (range) for continuous variables and percentage (count) for categorical variables. Chisquared or Fisher's exact test was used for analysis of categorical data, as appropriate. Demographic variables and comorbidities were compared between stroke patients and control subjects with Student's $t$ test. Spleen size was compared among stroke patients, uninfected and infected patients, and control subjects with oneway ANOVA followed by Bonferroni correction. The body temperature, median frequency of leukocytes, lymphocyte subpopulations, and serum level of circulating inflammatory markers were compared among stroke patients and control subjects at each time point with one-way ANOVA followed by Bonferroni correction. The lymphocyte subpopulations and serum levels of circulating inflammatory markers were also compared between infected and uninfected patients at the three time points with repeated measures ANOVA followed by Bonferroni correction. Analysis of covariance was used to compare the difference in lymphocyte subpopulations between patients with PCS or ACS after controlling for the NIHSS at the three time points. All continuous variables with the characteristic of homogeneity of variance distributed normally. The Tukey-Kramer adjustment was used to balance the sample size in different groups. Because of the small sample size, we did not compare differences in lymphocyte subpopulations or serum level of circulating inflammatory markers for each infection type (pulmonary infection, sepsis, and urinary tract infection). We used logistic regression to determine the relationship between cytokine levels, lymphocyte subpopulations, and infections. Pearson product-moment correlation was used for analysis of correlation between circulating inflammatory markers and lesion volume or NIHSS. The correlation between splenic volume and lymphocyte subpopulations was also evaluated with analysis of Pearson product-moment correlation. Statistical significance was set at $p<0.05$.

\section{ACKNOWLEDGMENTS}

We thank Claire Levine, MS, ELS, for assistance with this manuscript.

\section{CONFLICTS OF INTEREST}

There is no conflict of interest.

\section{GRANT SUPPORT}

This work was supported by grants from the National Natural Science Foundation of China (81301006) and the National Institutes of Health (R01NS078026, R01AT007317). 


\section{Authors' Contributions}

Study concept and design: Chao Jiang and Jian Wang. Acquisition of data: Weixia Kong, Yuejuan Wang, Fangfang Zuo, Fangfang Li, and Yali Wang. Assessment of lesion volume: Hongwei Xu. Measurement of spleen size: Weixia Kong. Flow cytometry and ELISA technique: Yuejuan Wang, Fangfang Zuo, Fangfang Li, and Yali Wang. Analysis and interpretation: Chao Jiang, Jian Wang, Weixia Kong, Jiewen Zhang, and Hong Lu. Critical revision of the manuscript for important intellectual content: Chao Jiang, Jian Wang, Wendy Ziai, Qingwu Yang, Hong Lu, Jiewen Zhang, and Jie Yang.

\section{REFERENCES}

1. Dirnagl U, Klehmet J, Braun JS, Harms H, Meisel C, Ziemssen T, Prass K and Meisel A. Stroke-induced immunodepression: experimental evidence and clinical relevance. Stroke. 2007; 38(2 Suppl):770-773.

2. Chamorro A, Horcajada JP, Obach V, Vargas M, Revilla M, Torres F, Cervera A, Planas AM and Mensa J. The Early Systemic Prophylaxis of Infection After Stroke study: a randomized clinical trial. Stroke. 2005; 36(7):1495-1500.

3. Perry L and Love CP. Screening for dysphagia and aspiration in acute stroke: a systematic review. Dysphagia. 2001; 16(1):7-18

4. Zhang $\mathrm{H}$ and Li X. Correlation between inflammatory factors and post-stroke pneumonia in diabetic patients. Experimental and therapeutic medicine. 2013; 6(1):105108.

5. Chamorro A, Urra X and Planas AM. Infection after acute ischemic stroke: a manifestation of brain-induced immunodepression. Stroke. 2007; 38(3):1097-1103.

6. Offner H, Vandenbark AA and Hurn PD. Effect of experimental stroke on peripheral immunity: CNS ischemia induces profound immunosuppression. Neuroscience. 2009; 158(3):1098-1111.

7. Shi L, Qin J, Song B, Wang QM, Zhang R, Liu X, Liu Y, Hou H, Chen X, Ma X, Jiang C, Sun X, Gong G and Xu $\mathrm{Y}$. Increased frequency of circulating regulatory $\mathrm{T}$ cells in patients with acute cerebral hemorrhage. Neuroscience letters. 2015; 591:115-120.

8. Yan FL and Zhang JH. Role of the sympathetic nervous system and spleen in experimental stroke-induced immunodepression. Medical science monitor. 2014; 20:2489-2496.

9. Gorczynski RM, Hadidi S, Yu G and Clark DA. The same immunoregulatory molecules contribute to successful pregnancy and transplantation. Am J Reprod Immunol. 2002; 48(1):18-26.

10. Zheng H, Du G, Zhao R, Tang B and Zhu N. Enhanced allogeneic skin-graft survival using sCD95L, sCD152, interleukin-10 and transforming growth factor-beta in combination, and comparison with ciclosporin. Clinical and experimental dermatology. 2009; 34(6):721-727.

11. Hug A, Liesz A, Muerle B, Zhou W, Ehrenheim J, Lorenz A, Dalpke A and Veltkamp R. Reduced efficacy of circulating costimulatory cells after focal cerebral ischemia. Stroke. 2011; 42(12):3580-3586.

12. Wang M, Tian T, Yu S, He N and Ma D. Th17 and Treg cells in bone related diseases. Clinical \& developmental immunology. 2013; 2013:203705.

13. Manicassamy S and Pulendran B. Dendritic cell control of tolerogenic responses. Immunological reviews. 2011; 241(1):206-227.

14. Shichita T, Ago T, Kamouchi M, Kitazono T, Yoshimura A and Ooboshi H. Novel therapeutic strategies targeting innate immune responses and early inflammation after stroke. Journal of neurochemistry. 2012; 123 Suppl 2:29-38.

15. Vogelgesang A, Grunwald U, Langner S, Jack R, Broker BM, Kessler C and Dressel A. Analysis of lymphocyte subsets in patients with stroke and their influence on infection after stroke. Stroke. 2008; 39(1):237-241.

16. Hug A, Dalpke A, Wieczorek N, Giese T, Lorenz A, Auffarth G, Liesz A and Veltkamp R. Infarct volume is a major determiner of post-stroke immune cell function and susceptibility to infection. Stroke. 2009; 40(10):3226-3232.

17. Klehmet J, Harms H, Richter M, Prass K, Volk HD, Dirnagl U, Meisel A and Meisel C. Stroke-induced immunodepression and post-stroke infections: lessons from the preventive antibacterial therapy in stroke trial. Neuroscience. 2009; 158(3):1184-1193.

18. Li L, Yiin GS, Geraghty OC, Schulz UG, Kuker W, Mehta $\mathrm{Z}$ and Rothwell PM. Incidence, outcome, risk factors, and long-term prognosis of cryptogenic transient ischaemic attack and ischaemic stroke: a population-based study. The Lancet Neurology. 2015; 14(9):903-913.

19. Ois A, Cuadrado-Godia E, Rodriguez-Campello A, GiraltSteinhauer E, Jimenez-Conde J, Lopez-Cuina M, Ley M, Soriano C and Roquer J. Relevance of stroke subtype in vascular risk prediction. Neurology. 2013; 81(6):575-580.

20. Gendron A, Teitelbaum J, Cossette C, Nuara S, Dumont M, Geadah D, du Souich P and Kouassi E. Temporal effects of left versus right middle cerebral artery occlusion on spleen lymphocyte subsets and mitogenic response in Wistar rats. Brain research. 2002; 955(1-2):85-97.

21. Sahota P, Vahidy F, Nguyen C, Bui TT, Yang B, Parsha K, Garrett J, Bambhroliya A, Barreto A, Grotta JC, Aronowski $\mathrm{J}$, Rahbar $\mathrm{MH}$ and Savitz S. Changes in spleen size in patients with acute ischemic stroke: a pilot observational study. International journal of stroke. 2013; 8(2):60-67.

22. Wang J, Yu L, Jiang C, Fu X, Liu X, Wang M, Ou C, Cui $\mathrm{X}$ and Zhou $\mathrm{C}$. Cerebral ischemia increases bone marrow $\mathrm{CD} 4+\mathrm{CD} 25+\mathrm{FoxP} 3+$ regulatory $\mathrm{T}$ cells in mice via signals from sympathetic nervous system. Brain, behavior, and immunity. 2015; 43:172-183.

23. Yan J, Read SJ, Henderson RD, Hull R, O’Sullivan JD, 
McCombe PA and Greer JM. Frequency and function of regulatory $\mathrm{T}$ cells after ischaemic stroke in humans. Journal of neuroimmunology. 2012; 243(1-2):89-94.

24. Urra X, Cervera A, Villamor N, Planas AM and Chamorro A. Harms and benefits of lymphocyte subpopulations in patients with acute stroke. Neuroscience. 2009; 158(3):1174-1183.

25. Kleinewietfeld $M$ and Hafler DA. The plasticity of human Treg and Th17 cells and its role in autoimmunity. Seminars in immunology. 2013; 25(4):305-312.

26. Liesz A, Hu X, Kleinschnitz $\mathrm{C}$ and Offner H. Functional role of regulatory lymphocytes in stroke: facts and controversies. Stroke. 2015; 46(5):1422-1430.

27. Shevach EM, DiPaolo RA, Andersson J, Zhao DM, Stephens GL and Thornton AM. The lifestyle of naturally occurring CD4+ CD25+ Foxp3+ regulatory $\mathrm{T}$ cells. Immunological reviews. 2006; 212:60-73.

28. Shichita $T$, Ito $M$ and Yoshimura A. Post-ischemic inflammation regulates neural damage and protection. Frontiers in cellular neuroscience. 2014; 8:319.

29. Lee KM, Stott RT, Zhao G, SooHoo J, Xiong W, Lian MM, Fitzgerald L, Shi S, Akrawi E, Lei J, Deng S, Yeh H, Markmann JF and Kim JI. TGF-beta-producing regulatory $\mathrm{B}$ cells induce regulatory $\mathrm{T}$ cells and promote transplantation tolerance. European journal of immunology. 2014; 44(6):1728-1736.

30. Prass K, Meisel C, Hoflich C, Braun J, Halle E, Wolf T, Ruscher K, Victorov IV, Priller J, Dirnagl U, Volk HD and Meisel A. Stroke-induced immunodeficiency promotes spontaneous bacterial infections and is mediated by sympathetic activation reversal by poststroke $\mathrm{T}$ helper cell type 1-like immunostimulation. The Journal of experimental medicine. 2003; 198(5):725-736.

31. Green AM, Difazio R and Flynn JL. IFN-gamma from CD4 $\mathrm{T}$ cells is essential for host survival and enhances CD8 T cell function during Mycobacterium tuberculosis infection. J Immunol. 2013; 190(1):270-277.

32. Villegas-Mendez A, Greig R, Shaw TN, de Souza JB, Gwyer Findlay E, Stumhofer JS, Hafalla JC, Blount DG, Hunter CA, Riley EM and Couper KN. IFN-gammaproducing $\mathrm{CD} 4+\mathrm{T}$ cells promote experimental cerebral malaria by modulating CD $8+\mathrm{T}$ cell accumulation within the brain. J Immunol. 2012; 189(2):968-979.

33. Gao L, Lu Q, Huang LJ, Ruan LH, Yang JJ, Huang WL, ZhuGe WS, Zhang YL, Fu B, Jin KL and ZhuGe QC. Transplanted neural stem cells modulate regulatory $\mathrm{T}$, gammadelta $\mathrm{T}$ cells and corresponding cytokines after intracerebral hemorrhage in rats. International journal of molecular sciences. 2014; 15(3):4431-4441.

34. Aslanyan S, Weir CJ, Diener HC, Kaste M and Lees KR. Pneumonia and urinary tract infection after acute ischaemic stroke: a tertiary analysis of the GAIN International trial. European journal of neurology. 2004; 11(1):49-53.

35. Chumbler NR, Williams LS, Wells CK, Lo AC, Nadeau S,
Peixoto AJ, Gorman M, Boice JL, Concato J and Bravata DM. Derivation and validation of a clinical system for predicting pneumonia in acute stroke. Neuroepidemiology. 2010; 34(4):193-199.

36. Bell CL, LaCroix A, Masaki K, Hade EM, Manini T, Mysiw WJ, Curb JD and Wassertheil-Smoller S. Prestroke factors associated with poststroke mortality and recovery in older women in the Women's Health Initiative. Journal of the American Geriatrics Society. 2013; 61(8):1324-1330.

37. Li L, Zhang LH, Xu WP and Hu JM. Risk assessment of ischemic stroke associated pneumonia. World journal of emergency medicine. 2014; 5(3):209-213.

38. Go S. Posterior Circulation Ischemic Stroke. Missouri medicine. 2015; 112(3):192-196.

39. Haeusler KG, Schmidt WU, Fohring F, Meisel C, Helms T, Jungehulsing GJ, Nolte CH, Schmolke K, Wegner B, Meisel A, Dirnagl U, Villringer A and Volk HD. Cellular immunodepression preceding infectious complications after acute ischemic stroke in humans. Cerebrovasc Dis. 2008; 25(1-2):50-58.

40. Shim $\mathrm{R}$ and Wong $\mathrm{CH}$. Ischemia, Immunosuppression and Infection-Tackling the Predicaments of Post-Stroke Complications. International journal of molecular sciences. 2016; 17(1).

41. Chamorro A, Amaro S, Vargas M, Obach V, Cervera A, Torres F and Planas AM. Interleukin 10, monocytes and increased risk of early infection in ischaemic stroke. Journal of neurology, neurosurgery, and psychiatry. 2006; 77(11):1279-1281.

42. Zeng L, Wang Y, Liu J, Wang L, Weng S, Chen K, Domino EF and Yang GY. Pro-inflammatory cytokine network in peripheral inflammation response to cerebral ischemia. Neuroscience letters. 2013; 548:4-9.

43. Shichita T, Sugiyama Y, Ooboshi H, Sugimori H, Nakagawa R, Takada I, Iwaki T, Okada Y, Iida M, Cua DJ, Iwakura Y and Yoshimura A. Pivotal role of cerebral interleukin-17-producing gammadeltaT cells in the delayed phase of ischemic brain injury. Nature medicine. 2009; 15(8):946-950.

44. Jiang C, Wang J, Li X, Liu C, Chen N and Hao Y. Progesterone exerts neuroprotective effects by inhibiting inflammatory response after stroke. Inflammation research. 2009; 58(9):619-624.

45. Jiang C, Cui K, Wang J and He Y. Microglia and cyclooxygenase-2: possible therapeutic targets of progesterone for stroke. International immunopharmacology. 2011; 11(11):1925-1931.

46. Theriault P, Le Behot A, ElAli A and Rivest S. Sub-acute systemic erythropoietin administration reduces ischemic brain injury in an age-dependent manner. Oncotarget. 2016; 7:35552-35561. doi: 10.18632/oncotarget.9652.

47. Cekanaviciute E, Fathali N, Doyle KP, Williams AM, Han J and Buckwalter MS. Astrocytic transforming growth factorbeta signaling reduces subacute neuroinflammation after 
stroke in mice. Glia. 2014; 62(8):1227-1240.

48. Liesz A, Suri-Payer E, Veltkamp C, Doerr H, Sommer C, Rivest S, Giese T and Veltkamp R. Regulatory T cells are key cerebroprotective immunomodulators in acute experimental stroke. Nature medicine. 2009; 15(2):192-199.

49. Inacio AR, Bucala $\mathrm{R}$ and Deierborg $\mathrm{T}$. Lack of macrophage migration inhibitory factor in mice does not affect hallmarks of the inflammatory/immune response during the first week after stroke. Journal of neuroinflammation. 2011; 8:75.

50. Liu ZJ, Yang QD, Liu YH, Huang XS and Zhang N. Changes and clinical significance of serum IL-6, sICAM-1 in patients with cerebral infarcts. Journal of Central South University Medical sciences. 2004; 29(3):326-329.

51. Idicula TT, Brogger J, Naess H, Waje-Andreassen U and Thomassen L. Admission C-reactive protein after acute ischemic stroke is associated with stroke severity and mortality: the 'Bergen stroke study'. BMC neurology. 2009; 9:18.

52. Wang JH, Zhang YW, Zhang $\mathrm{P}$, Deng BQ, Ding $\mathrm{S}$, Wang ZK, Wu T and Wang J. CD40 ligand as a potential biomarker for atherosclerotic instability. Neurological research. 2013; 35(7):693-700.

53. $\mathrm{Gu} \mathrm{LJ}$, Xiong $\mathrm{XX}$, Ito $\mathrm{T}$, Lee $\mathrm{J}, \mathrm{Xu} \mathrm{BH}$, Krams $\mathrm{S}$, Steinberg GK and Zhao H. Moderate hypothermia inhibits brain inflammation and attenuates strokeinduced immunodepression in rats. CNS neuroscience \& therapeutics. 2014; 20(1):67-75.

54. Mrakovcic-Sutic I, Tokmadzic VS, Laskarin G, Mahmutefendic H, Lucin P, Zupan Z and Sustic A. Early changes in frequency of peripheral blood lymphocyte subpopulations in severe traumatic brain-injured patients. Scandinavian journal of immunology. 2010; 72(1):57-65.
55. Illanes S, Liesz A, Sun L, Dalpke A, Zorn M and Veltkamp R. Hematoma size as major modulator of the cellular immune system after experimental intracerebral hemorrhage. Neuroscience letters. 2011; 490(3):170-174.

56. Bramer D, Hoyer H, Gunther A, Nowack S, Brunkhorst FM, Witte OW and Hoyer D. Study protocol: prediction of stroke associated infections by markers of autonomic control. BMC neurology. 2014; 14:9.

57. Yetter EM, Acosta KB, Olson MC and Blundell K. Estimating splenic volume: sonographic measurements correlated with helical CT determination. AJR American journal of roentgenology. 2003; 181(6):1615-1620.

58. Law JP, Hirschkorn DF, Owen RE, Biswas HH, Norris PJ and Lanteri MC. The importance of Foxp3 antibody and fixation/permeabilization buffer combinations in identifying CD4+CD25+Foxp3+ regulatory T cells. Cytometry Part A. 2009; 75(12):1040-1050.

59. Terroni L, Amaro E, Iosifescu DV, Tinone G, Sato JR, Leite CC, Sobreiro MF, Lucia MC, Scaff M and Fraguas R. Stroke lesion in cortical neural circuits and poststroke incidence of major depressive episode: a 4-month prospective study. The world journal of biological psychiatry. 2011; 12(7):539-548.

60. Umemura T, Senda J, Fukami Y, Mashita S, Kawamura T, Sakakibara $\mathrm{T}$ and Sobue G. Impact of albuminuria on early neurological deterioration and lesion volume expansion in lenticulostriate small infarcts. Stroke. 2014; 45(2):587-590. 